\title{
UPAYA PERBAIKAN PERTUMBUHAN BIBIT MERBAU DARAT (Intsia palembanica) DENGAN NAUNGAN DAN PEMUPUKAN
}

\author{
(SEEDLING IMPROVEMENT GROWTH OF MIRABOW \\ (Intsia palembanica) WITH SHADING AND FERTILIZATION)
}

\author{
Esra Maradong Simangunsong, Melya Riniarti, dan Duryat \\ Jurusan Kehutanan Fakultas Pertanian Universitas lampung \\ Jl. Soemantri Brojonegoro No. 1 Bandar Lampung \\ E-mail : esramaradong@gmail.com No. Telepon : 081397068233
}

\begin{abstract}
ABSTRAK
Merbau darat (Intsia palembanica) merupakan tumbuhan hutan yang memiliki kayu dengan kelas awet I, II dan kelas kuat I, II. Kayu ini dikenal memiliki serat yang lurus, dapat dijadikan bahan kayu lapis, panel, meubel, ukiran, alat-alat musik dan permukaan kayu mengkilap indah. Beberapa faktor yang mempengaruhi pertumbuhan tanaman adalah naungan dan unsur hara. Penelitian ini bertujuan untuk mengetahui pengaruh pemberian naungan dan pemupukan terhadap pertumbuhan bibit merbau darat. Penelitian ini disusun dalam rancangan acak kelompok (RAK) dengan 4 kelompok dan 3 perlakuan. Kelompok pada penelitian ini adalah intensitas naungan $0 \%, 55 \%, 65 \%$, dan $75 \%$, sedangkan perlakuan dalam penelitian ini adalah pemberian pupuk majemuk NPK dengan konsentrasi $0 \mathrm{~g}$ (kontrol), $2 \mathrm{~g} /$ polybag, dan $4 \mathrm{~g} /$ polybag. Besarnya setiap satuan percobaan yang digunakan terdiri dari 1 bibit. Variabel pengamatan adalah pertambahan tinggi, pertambahan diameter, panjang akar, jumlah daun, nisbah tajuk dan akar, berat kering pucuk, berat kering akar, berat kering total dan indeks mutu bibit. Setelah data homogen, dilakukan analisis sidik ragam. Analisis lanjutan dilakukan dengan uji beda nyata terkecil. Seluruh pengujian dilakukan pada taraf nyata 5\%. Hasil penelitian menunjukkan bahwa pemberian intensitas naungan 55\% meningkatkan berat kering pucuk bibit merbau darat, tetapi pemberian intensitas naungan diatas $65 \%$ atau lebih justru menurunkan berat kering pucuk dan berat kering total bibit merbau darat. Sementara pemberian pupuk majemuk NPK dengan dosis $4 \mathrm{~g} /$ polybag memberikan pengaruh terbaik terhadap jumlah daun, nisbah tajuk akar, berat kering pucuk dan berat kering total bibit merbau darat.
\end{abstract}

Kata kunci : merbau darat, naungan, pupuk

\section{ABSTRACT}

Mirabow (Intsia palembanica) is one of high quality tropical wood. The wood of mirabow is categorized in durable class I, II and strong class I, II. Mirabow has the straight wood fiber, can be used as plywood, panels, furniture, musical instrument and beautiful shiny wood surface. Among the factors that affect plant growth were shading intensity and nutrients. The purpose of the research were to figure out the effect of shading intensity and fertilization to the growth of mirabow. The Block Randomized Design (BRD) of 4 groups and 3 treatment was employed as research design. Group of the reseach was the provision of no shading $(0 \%)$, shading intensity 55\%, shading intensity $65 \%$, and shading intensity $75 \%$, meanwhile the dose of NPK fertilizer of $0 \mathrm{~g} /$ polybag, $2 \mathrm{~g} /$ polybag, and $4 \mathrm{~g} /$ polybag were employed as the treatments. The large of experimental unit were used 1 seedling. The variable that was observed were high accretion, diameter accretion, root length, number of leaves, crown root ratio, dry weight of crown, dry weight of root, total dry weight and quality index of seedling. Bartlett test was employed to figure out the homogenity of datas. Then, analysis of variance 
was used to the least significant difference. The entire data tested on 5\% significant level. The results showed that 55\% shading intensity, obviously increase the dry weight of crown, however the shading intensity more than $65 \%$ in fact, evidently decrease the dry weight crown and total dry weight of mirabow seedling. The dose of $4 \mathrm{~g} /$ polybag of NPK fertilizer, evidently the number of leaves, crown root ratio, dry weight of crown and total dry weight of mirabow seedling.

Keywords : mirabow, seed fertilisation, shading intensity

\section{PENDAHULUAN}

Pohon merbau darat (Intsia palembanica) merupakan salah satu tumbuhan hutan yang bernilai ekonomi tinggi. Merbau memiliki serat kayu yang lurus, permukaan kayu mengkilap indah, dapat dijadikan bahan kayu lapis yang sangat awet dan baik. Kayu merbau yang berasal dari Maluku dapat dijadikan venir dengan sudut kupas $92^{0}$, dapat menghasilkan venir setebal 1,5 mm tanpa adanya perlakuan pendahuluan (Martawijaya dkk., 2005).

Merbau darat banyak digunakan sebagai bahan untuk pembuatan meubel, panel, ukiran, badan truk, dan alat-alat musik. Karena sifatnya yang tahan terhadap serangga dan hama penggerek laut, kayu merbau banyak digunakan untuk kontruksi perairan seperti, dermaga, jembatan, dan pintu air (Martawijaya dkk., 2005). Kualitas merbau yang unggul menyebabkan terjadinya penebangan liar dan membuat tanaman ini semakin langka, sehingga perlu dilakukan upaya budidaya tanaman untuk meningkatkan pembangunan hutan tanaman. Salah satu upaya untuk mendukung pembangunan hutan tanaman diperlukan ketersediaan bibit merbau. Pembibitan merbau masih mengalami banyak kendala diantaranya tingkat kematian bibit di persemaian cukup tinggi.

Untuk meningkatkan keberhasilan pembibitan perlu dilakukan perlakuan-perlaku-an khusus seperti perbaikan media tumbuh, pemberian naungan, pemupukan dan lain-lain. Pemberian naungan perlu dilakukan pada pembibitan, karena jenis bibit memiliki toleransi naungan yang berbeda-beda menurut umur dan kondisi lingku-ngan. Pemberian naungan yang tepat pada bibit merbau darat diharapkan mening-katkan keberhasilan pertumbuhan bibit. Panjaitan dkk., (2011) melaporkan bahwa pemberian naungan sebesar $65 \%$ memberikan pengaruh terbaik terhadap pertumbuhan tinggi semai, diameter batang, berat segar semai, dan berat kering pada semai Shorea selanica di persemaian.

Selain pemberian naungan, bibit memerlukan bahan lain untuk memperbaiki sifat tanah sehingga dapat menghasilkan pertumbuhan yang lebih baik. Perbaikan me-dia dapat dilakukan dengan pemupukan karena dengan suplai hara dari pupuk dapat memacu pertumbuhan tunas maupun akar dan dapat meningkatkan daya tahan tanaman terhadap kekurangan air atau serangan penyakit (Adinugraha, 2012).

Tujuan penelitian ini adalah untuk mengetahui pengaruh intensitas naungan terhadap pertumbuhan bibit merbau darat dan mengetahui pengaruh pemberian dosis pupuk terhadap pertumbuhan bibit merbau darat. Hipotesis yang diajukan adalah pemberian naungan akan meningkatkan pertumbuhan bibit merbau darat dan pemberian dosis pupuk $4 \mathrm{~g} /$ polybag merupakan dosis terbaik dibandingkan dosis $2 \mathrm{~g} /$ polybag atau $0 \mathrm{~g}$ (kontrol) untuk pertumbuhan bibit merbau darat.

\section{METODE PENELITIAN}

\section{Lokasi dan Waktu Penelitian}

Penelitian dilaksanakan di rumah kaca Fakultas Pertanian Universitas Lampung, Bandar Lampung. Penelitian berlangsung selama 3 bulan, yaitu pada Mei—Juli 2014. 


\section{Bahan dan Alat}

Bahan-bahan yang digunakan yaitu benih merbau darat, pasir, tanah, pupuk maje-muk NPK (15-15-15), paranet dengan intensitas naungan 55\%, 65\%, dan 75\%. Alat yang digunakan adalah bak kecambah berukuran $(30 \mathrm{~cm} \times 25 \mathrm{~cm} \times 10 \mathrm{~cm})$, cangkul, cetok, gembor, polybag ukuran $(20 \mathrm{~cm} \times 15 \mathrm{~cm})$, kaliper dengan ketelitian $0,01 \mathrm{~cm}$, penggaris dengan ketelitian $0,05 \mathrm{~cm}$, timbangan digital dengan ketelitian 0,0001 $\mathrm{g}$, oven, lux meter, thermometer air dan software SPSS 18.

\section{Metode Penelitian}

\section{Rancangan Percobaan}

Penelitian ini disusun dengan menggunakan Rancangan Acak Kelompok (RAK). Percobaan ini terdiri dari 4 kelompok yaitu tanpa naungan, naungan $55 \%$, naungan $65 \%$ dan naungan $75 \%$. Terdapat 3 perlakuan dalam penelitian ini, yaitu perbedaan dosis pupuk NPK yang terdiri dari $0 \mathrm{~g}$ (kontrol), $2 \mathrm{~g} /$ polybag dan $4 \mathrm{~g} /$ polybag, besarnya setiap satuan percobaan yang digunakan terdiri dari 1 bibit.

\section{Kegiatan Penelitian}

a. Persiapan benih. Benih diperoleh dari pohon merbau darat yang ada di Arboretum Fakultas Pertanian Universitas Lampung. Buah yang telah terkum-pul kemudian diekstraksi yaitu memisahkan benih dari kulit buahnya. Kemudian dilakukan proses penyeleksian, penyeleksian benih dilakukan dengan cara merendam benih ke dalam air, benih yang terapung tidak diguna-kan, diduga benih tersebut rusak. Benih yang sudah diseleksi kemudian diska-rifikasi dengan cara merendam benih dengan air bersuhu awal $65^{0} \mathrm{C}-75^{0} \mathrm{C}$ selama 24 jam (Indriyanto, 2013).

b. Perkecambahan benih. Benih merbau darat yang telah diskarifikasi kemudian dikecambahkan pada bak kecambah ukuran $(30 \mathrm{~cm}$ x $25 \mathrm{~cm}$ x $10 \mathrm{~cm})$ yang telah diberi pasir. Sebelumnya pasir yang digunakan diayak untuk mendapat-kan media yang halus dan kemudian dikeringanginkan selama 2 x 24 jam.

c. Persiapan media sapih. Media sapih yang digunakan adalah tanah lapisan atas (top soil) yang sudah digemburkan dan dibersihkan. Proses penggemburan dilakukan agar mendapatkan struktur dan bentuk yang seragam.

d. Penyapihan. Penyapihan semai dari bak kecambah ke polybag dilakukan setelah benih tumbuh memiliki sepasang daun yang telah terbuka, dan batang bibit/kecambah kokoh (Kurniaty dan Danu , 2012). Penyapihan dilakukan pada pagi hari untuk menghindari terjadinya penguapan (evapotranspirasi).

e. Pemberian naungan. Bibit yang telah disapih dimasukkan ke dalam polybag $(20 \mathrm{~cm} \mathrm{x}$ $15 \mathrm{~cm}$ ) dengan media sapih tanah lapisan atas (top soil). Setiap bibit diletakkan dalam bedengan dengan intensitas naungan yaitu, tanpa naungan 0\% (N0), naungan 55\% (N1), naungan $65 \%(\mathrm{~N} 2)$, dan naungan $75 \%(\mathrm{~N} 3)$.

f. Pemupukan. Pemupukan dilakukan 2 kali yaitu 1 minggu setelah disapih dan 5 minggu setelah disapih. Pupuk yang digunakan yaitu pupuk NPK majemuk dengan dosis $0 \mathrm{~g}$ (kontrol), $2 \mathrm{~g} /$ polybag, dan $4 \mathrm{~g} /$ polybag.

g. Pemeliharaan Bibit. Pemeliharaan bibit meliputi penyiraman yang dilakukan sekali sehari setelah penyapihan yaitu pada waktu pagi hari, dan penyiangan gulma dilakukan secara berkala dengan cara mencabut tumbuhan pengganggu

\section{Pengamatan}

Parameter yang diamati dalam percobaan ini adalah. 
a. Pertambahan tinggi. Pertambahan tinggi merupakan selisih tinggi bibit pada akhir penelitian dengan tinggi bibit bibit pada saat penyapihan. Pengukuran dilakukan 2 kali yaitu pada saat semai disapih dan pada saat akhir penelitian.

b. Pertambahan diameter. Pertambahan diameter merupakan selisih diameter bibit pada akhir penelitian dengan diameter pada saat penyapihan. Pengukuran dilakukan 2 kali yaitu pada saat semai disapih dan pada saat akhir penelitian.

c. Panjang akar semai (cm/tanaman). Panjang akar semai diukur dari pangkal batang sampai ujung akar menggunakan pengaris dengan ketelitian $0,05 \mathrm{~cm}$. Pengukuran dilakukan sekali pada akhir pengamatan.

d. Jumlah daun. Jumlah daun dihitung berdasarkan helaian daun yang tumbuh selama pengamatan. Penghitungan jumlah daun dilakukan pada akhir penga-matan.

e. Nisbah tajuk dan akar bibit. Pengukuran berat kering ini dilakukan pada akhir pengamatan. Setiap bibit dipotong menjadi dua bagian, bagian tajuk dan akar. Dari hasil penimbangan berat kering dihitung ratio tajuk dan akar bibit dengan rumus:

$$
\text { Nisbah tajuk - akar : } \frac{\text { Berat kering tajuk }}{\text { Berat kering akar }}
$$

f. Bobot kering total (g/tanaman). Pengukuran bobot kering total dilakukan pada akhir pengamatan dengan menimbang berat kering tajuk menjumlahkan berat kering akar setelah di oven suhu $80^{\circ} \mathrm{C}$ hingga bobot keringnya konstan.

\section{Bobot kering total $($ BKT $)=$ Berat kering tajuk + Berat kering akar}

g. Indeks mutu bibit (IMB). Untuk mengetahui kualitas bibit secara fisiologis, maka dihitung dengan menggunakan cara Dickson (1960) dalam Hendromono (1994) dengan rumus sebagai berikut.

$$
\text { Indeks Mutu }=\frac{\text { Bobot kering batang } \mathrm{g}+\text { bobot kering akar }(\mathrm{g})}{\frac{\text { tinggi } \left.^{(} \mathrm{cm}\right)}{\text { diameter }(\mathrm{cm})}+\frac{\text { Bobot kering batang } \bar{g}(\mathrm{~g})}{\text { Bobot kering akar }(\mathrm{g})}}
$$

\section{Analisis Data}

a. Homogenitas Ragam

Untuk menguji homogenitas ragam, dilakukan Uji Bartlett dengan taraf nyata 5\% (Gaspersz, 1994).

\section{b. Analisis Ragam}

Untuk menguji hipotesis ada atau tidaknya pengaruh faktor perlakuan terhadap parameter yang diamati, dilakukan analisis sidik ragam (uji F) dengan taraf nyata $5 \%$.

\section{c. Uji Beda Nyata Terkecil (BNT)}

Untuk menunjukkan perbedaan masing-masing perlakuan atau beda nyata antar perlakuan, dilakukan uji Beda Nyata Terkecil (BNT) dengan taraf nyata 5\% (Hanafiah, 2011).

\section{HASIL DAN PEMBAHASAN}

\section{Hasil}

Berdasarkan hasil analisis sidik ragam, diketahui bahwa terdapat paling tidak satu perlakuan naungan yang berpengaruh nyata terhadap berat kering pucuk dan berat kering total. Terdapat paling tidak satu perlakuan pemupukan yang berpengaruh nyata terhadap jumlah daun, nisbah tajuk dan akar, berat kering pucuk dan berat kering total bibit merbau darat. Rekapitulasi hasil analisis ragam disajikan pada Tabel 1 berikut. 
Tabel 1. Rekapitulasi analisis sidik ragam perbaikan pertumbuhan bibit merbau darat dengan naungan dan pemupukan.

\begin{tabular}{|c|c|c|c|c|c|c|c|c|c|}
\hline Perlakuan & $\begin{array}{c}\mathrm{T} \\
(\mathrm{cm})\end{array}$ & $\begin{array}{c}\mathrm{D} \\
(\mathrm{mm})\end{array}$ & $\begin{array}{l}\text { PA } \\
(\mathrm{cm})\end{array}$ & $\begin{array}{c}\text { JD } \\
\text { (helai) }\end{array}$ & NTA & $\begin{array}{c}\text { BKP } \\
(\mathrm{g})\end{array}$ & $\begin{array}{c}\text { BKA } \\
(\mathrm{g})\end{array}$ & $\begin{array}{c}\text { BKT } \\
(\mathrm{g})\end{array}$ & IMB \\
\hline Kelompok & $2,52 \mathrm{tn}$ & $0,20 \mathrm{tn}$ & $1,02 \mathrm{tn}$ & $0,80 \mathrm{tn}$ & $1,49 \mathrm{tn}$ & $7,36^{*}$ & $4,28 \mathrm{tn}$ & $7,02 *$ & $1,14 \mathrm{tn}$ \\
\hline Pupuk & $2,69 \mathrm{tn}$ & $0,63 \mathrm{tn}$ & $0,85 \mathrm{tn}$ & $22,93 *$ & $9,87 *$ & $37,12 *$ & $0,93 \mathrm{tn}$ & $25,30 *$ & $2,41 \mathrm{tn}$ \\
\hline \multicolumn{10}{|l|}{ Keterangan : } \\
\hline \multirow{2}{*}{\multicolumn{5}{|c|}{ * : berbeda nyata pada taraf nyata $5 \%$}} & NTA & \multicolumn{4}{|c|}{ : nisbah tajuk dan akar } \\
\hline & & & & & BKP & \multicolumn{4}{|c|}{ : bobot kering pucuk } \\
\hline \multicolumn{5}{|c|}{$\Delta \mathrm{T}:$ pertambahan tinggi bibit merbau darat } & BKA & \multicolumn{4}{|c|}{ : bobot kering akar } \\
\hline \multicolumn{5}{|c|}{$\Delta \mathrm{D}:$ pertambahan diameter bibit merbau darat } & BKT & \multicolumn{4}{|c|}{ : berat kering total } \\
\hline \multicolumn{5}{|c|}{ PA : panjang akar } & IMB & : ind & mutu bil & & \\
\hline \multicolumn{10}{|c|}{ JD : jumlah daun } \\
\hline
\end{tabular}

Untuk mengetahui perlakuan yang memberi pengaruh nyata terhadap pertumbu-han bibit merbau darat, maka dilakukan uji lanjut dengan uji Beda Nyata Terkecil (BNT). Rekapitulasi hasil analisis uji BNT pada pertumbuhan bibit merbau darat, disajikan pada Tabel 2 dan 3.

Tabel 2. Rekapitulasi hasil uji BNT upaya perbaikan pertumbuhan bibit merbau darat dengan naungan pada berbagai parameter pertumbuhan.

\begin{tabular}{cccccccccc}
\hline Kelompok & $\begin{array}{c}\mathrm{T} \\
(\mathrm{cm})\end{array}$ & $\begin{array}{c}\mathrm{D} \\
(\mathrm{mm})\end{array}$ & $\begin{array}{c}\text { PA } \\
(\mathrm{cm})\end{array}$ & $\begin{array}{c}\text { JD } \\
(\text { helai })\end{array}$ & $\begin{array}{c}\text { NTA } \\
\text { BNP } \\
(\mathrm{g})\end{array}$ & $\begin{array}{c}\text { BKA } \\
(\mathrm{g})\end{array}$ & $\begin{array}{c}\text { BKT } \\
(\mathrm{g})\end{array}$ & IMB \\
\hline N0 & $35,15 \mathrm{a}$ & $2,13 \mathrm{a}$ & $23,21 \mathrm{a}$ & $14,62 \mathrm{a}$ & $4,59 \mathrm{a}$ & $5,36 \mathrm{~b}$ & $1,25 \mathrm{a}$ & $6,67 \mathrm{a}$ & $1,81 \mathrm{a}$ \\
N1 & $41,56 \mathrm{a}$ & $2,07 \mathrm{a}$ & $22,94 \mathrm{a}$ & $15,58 \mathrm{a}$ & $4,75 \mathrm{a}$ & $5,40 \mathrm{a}$ & $1,15 \mathrm{a}$ & $6,59 \mathrm{a}$ & $1,95 \mathrm{a}$ \\
N2 & $41,11 \mathrm{a}$ & $2,23 \mathrm{a}$ & $21,51 \mathrm{a}$ & $13,96 \mathrm{a}$ & $4,02 \mathrm{a}$ & $4,98 \mathrm{c}$ & $1,25 \mathrm{a}$ & $6,23 \mathrm{a}$ & $1,89 \mathrm{a}$ \\
N3 & $34,22 \mathrm{a}$ & $2,10 \mathrm{a}$ & $20,72 \mathrm{a}$ & $14,46 \mathrm{a}$ & $4,72 \mathrm{a}$ & $4,03 \mathrm{~d}$ & $0,88 \mathrm{a}$ & $4,92 \mathrm{~d}$ & $2,10 \mathrm{a}$ \\
\hline BNT & 8,42 & 0,53 & 4,05 & 2,62 & 0,97 & 0,81 & 0,29 & 1,06 & 0,38 \\
\hline
\end{tabular}

Keterangan :

$\Delta \mathrm{T} \quad$ : pertambahan tinggi bibit merbau darat

$\Delta \mathrm{D} \quad$ : pertambahan diameter bibit merbau darat

PA : panjang akar

JD : jumlah daun

NTA : nisbah tajuk dan akar

BKP : bobot kering pucuk

BKA : bobot kering akar

$\begin{array}{ll}\text { IMB } & \text { : indeks mutu bibit } \\ \text { N0 } & \text { : tanpa naungan (kontrol) } \\ \text { N1 } & \text { naungan dengan intensitas } 55 \% \\ \text { N2 } & \text { naungan dengan intensitas } 65 \% \\ \text { N3 } & \text { : naungan dengan intensitas } 75 \%\end{array}$

Tabel 3. Rekapitulasi hasil uji BNT upaya perbaikan pertumbuhan bibit merbau darat dengan pemupukan pada berbagai parameter pertumbuhan.

\begin{tabular}{|c|c|c|c|c|c|c|c|c|c|}
\hline Perlakuan & $\begin{array}{c}\mathrm{T} \\
(\mathrm{cm})\end{array}$ & $\begin{array}{c}\mathrm{D} \\
(\mathrm{mm})\end{array}$ & $\begin{array}{l}\text { PA } \\
(\mathrm{cm})\end{array}$ & $\begin{array}{c}\text { JD } \\
\text { (helai) }\end{array}$ & NTA & $\begin{array}{c}\text { BKP } \\
(\mathrm{g})\end{array}$ & $\begin{array}{c}\text { BKA } \\
(\mathrm{g})\end{array}$ & $\begin{array}{l}\text { BKT } \\
(\mathrm{g})\end{array}$ & IMB \\
\hline $\mathrm{P} 0$ & $34,10 \mathrm{a}$ & $2,01 \mathrm{a}$ & $21,06 \mathrm{a}$ & $11,03 \mathrm{~b}$ & $3,65 \mathrm{~b}$ & $3,55 \mathrm{c}$ & $1,06 \mathrm{a}$ & $4,62 \mathrm{c}$ & $2,13 \mathrm{a}$ \\
\hline P1 & $39,25 \mathrm{a}$ & $2,19 \mathrm{a}$ & $22,34 \mathrm{a}$ & $16,31 \mathrm{a}$ & $4,87 \mathrm{a}$ & $5,37 \mathrm{~b}$ & $1,14 \mathrm{a}$ & $6,52 \mathrm{a}$ & $1,86 \mathrm{a}$ \\
\hline $\mathrm{P} 2$ & $40,67 \mathrm{a}$ & $2,19 \mathrm{a}$ & $22,88 \mathrm{a}$ & $16,63 \mathrm{a}$ & $5,05 \mathrm{a}$ & $5,91 \mathrm{a}$ & $1,20 \mathrm{a}$ & $7,18 \mathrm{a}$ & $1,83 \mathrm{a}$ \\
\hline BNT & 7,29 & 0,46 & 3,51 & 2,27 & 0,84 & 0,70 & 0,25 & 0,92 & 0,33 \\
\hline
\end{tabular}

Keterangan :

$\Delta \mathrm{T} \quad:$ pertambahan tinggi bibit merbau darat

$\Delta \mathrm{D} \quad$ : pertambahan diameter bibit merbau darat

PA : panjang akar

JD : jumlah daun

NTA : nisbah tajuk dan akar

BKT : berat kering total

BKP : bobot kering pucuk

$\begin{array}{ll}\text { BKA } & \text { : bobot kering akar } \\ \text { IMB } & \text { : indeks mutu bibit } \\ \text { P0 } & \text { : tanpa pupuk } \\ \text { P1 } & \text { : pupuk dengan dosis } 2 \mathrm{~g} \mathrm{NPK} \\ \text { P2 } & \text { : pupuk dengan dosis } 4 \mathrm{~g} \mathrm{NPK}\end{array}$

Angka yang diikuti dengan huruf yang sama menunjukkan tidak berbeda nyata pada nilai BNT 5\%. 
Tabel 4. Pengukuran intensitas cahaya matahari menggunakan Lux meter.

\begin{tabular}{ccccc}
\hline $\begin{array}{c}\text { Waktu } \\
\text { pengamatan }\end{array}$ & $\begin{array}{c}\text { Tanpa } \\
\text { naungan } \\
(\text { Lux })\end{array}$ & $\begin{array}{c}\text { Intensitas } \\
\text { naungan 55\% } \\
\text { (Lux) }\end{array}$ & $\begin{array}{c}\text { Intensitas } \\
\text { naungan 65\% } \\
\text { (Lux) }\end{array}$ & $\begin{array}{c}\text { Intensitas } \\
\text { naungan 75\% } \\
\text { (Lux) }\end{array}$ \\
\hline Pagi & 1.206 & 410 & 367 & 307 \\
Siang & 2.251 & 1.961 & 1.055 & 615 \\
Sore & 783 & 288 & 254 & 227 \\
\hline Total & 4.240 & 2.659 & 1.676 & 1.149 \\
\hline $\begin{array}{c}\text { Persentase } \\
\text { intensitas cahaya } \\
\text { yang masuk }\end{array}$ & $100 \%$ & $62,71 \%$ & $39,52 \%$ & $27,09 \%$ \\
\hline
\end{tabular}

Semakin besar intensitas naungan yang diberikan, maka jumlah intensitas sinar matahari yang diterima oleh tanaman akan menjadi semakin kecil. Intensitas cahaya yang terlalu besar akan menyebabkan pertumbuhan semai toleran menjadi terhambat. Sedangkan intensitas cahaya yang terlalu kecil akan menyebabkan tanaman etiolasi.

\section{Pembahasan}

Naungan merupakan suatu upaya manipulasi terhadap masuknya sinar matahari yang diterima oleh tanaman. Untuk beberapa jenis tanaman hutan naungan diperlukan untuk mengurangi penguapan (transpirasi) tanaman dan memper-tahankan kelembaban dipersemaian sehingga tanaman dapat terus tumbuh. Tetapi untuk beberapa jenis tanaman intoleran justru keberadaan naungan akan meng-hambat pertumbuhan tanaman karena terjadinya penghambatan untuk menda-patkan sinar matahari.

Intensitas cahaya matahari berkaitan dengan fotosintesis. Fotosintesis menghasil-kan fotosintat yang disimpan dalam bentuk biomassa atau berat kering total. Jika nilai Berat Kering Total (BKT) semakin besar maka semakin besar pula nilai bio-massanya. Semakin besar nilai biomassanya maka pertumbuhan bibit yang dihasilkan akan semakin baik. Hal ini diperkirakan karena tanaman selama masa tertentu akan membentuk biomassa pada bagian tubuh tanaman yang menghasilkan pertambahan berat dan pertambahan ukuran lain (Sitompul dan Guritno, 1995).

Berdasarkan hasil penelitian diketahui bahwa perlakuan naungan memberikan hasil yang berpengaruh terhadap berat kering pucuk. Pemberian intensitas naungan 55\% meningkatkan berat kering pucuk bibit, tetapi pemberian intensita naungan diatas $65 \%$ atau lebih justru menurunkan berat kering pucuk dan berat kering total bibit, dengan menurunnya intensitas naungan maka akan menurunkan suhu lingkungan tanaman, yang mengakibatkan respirasi tanaman menurun. Sehingga menyebabkan berat kering pucuk pada tanaman menurun. Rendahnya pertumbuhan tanaman merbau darat yang diberi naungan diatas 65\% diduga karena masukan intensitas cahaya kurang memenuhi kebutuhan tanaman dalam mendukung proses pertumbuhannya. Diperkuat dengan penelitian Panjaitan dkk. (2011), bahwa pemberian naungan yang terlalu berat (75\%) memberikan pengaruh yang jelek terhadap pertumbuhan semai Shorea selanica. Bibit merbau darat merupakan jenis pohon yang membutuhkan radiasi matahari sedang atau membutuhkan naungan ringan untuk pertumbuhannya. Intensitas cahaya matahari sebesar $62,71 \%$ akan meningkatkan pertumbuhan bibit merbau darat, tetapi intensitas cahaya matahari $<62,71 \%$ akan menurunkan pertumbuhannya.

Fotosintesis pada tanaman dipengaruhi oleh beberapa faktor diantaranya adalah luas daun, jumlah klorofil, serta faktor lingkungan. Luas daun berkaitan dengan kapasitas penyerapan cahaya. Cahaya yang diserap daun digunakan untuk sintesis klorofil yang kemudian dirubah menjadi energi kimia pada proses fotosintesis. (Setyanti dkk., 2013). Saat 
masih muda umumnya tanaman memerlukan cahaya dengan intensitas yang relatif rendah dan seterusnya menjelang dewasa mulai memerlukan cahaya dengan intensitas yang lebih tinggi. Selanjutnya dikemukakan juga bawah laju fotosintesis akan sebanding dengan intensitas cahaya matahari yang diterima dan respirasi. Akan tetapi, pada titik jenuh cahaya, tanaman tidak mampu lagi menambah hasil fotosintesis walaupun jumlah cahaya bertambah (Wardiana dan Herman, 2009).

Pertumbuhan tanaman sangat dipengaruhi oleh ketersediaan unsur hara dalam ta-nah. Oleh karena itu, pemupukan sangat diperlukan untuk membantu pertumbu-han tanaman. Pupuk majemuk NPK merupakan pupuk yang menyediakan unsur hara esensial yang sangat dibutuhkan untuk pertumbuhan bibit. Hasil penelitian, menunjukkan bahwa perlakuan pemberian pupuk berpengaruh terhadap jumlah daun, nisbah tajuk dan akar, berat kering pucuk dan berat kering total bibit merbau darat. Perlakuan pupuk $4 \mathrm{~g} /$ polybag memiliki nilai yang tinggi dan mempunyai pertambahan daun yang lebih banyak dibandingkan perlakuan lainnya. Hal ini diduga karena unsur hara yang terdapat dalam pupuk majemuk NPK berperan penting dalam meningkatkan pertumbuhan bibit sehingga menghasilkan jumlah daun yang lebih banyak.

Menurut Rahmawati dkk. (2013), pertumbuhan akar yang baik akan mempengaruhi perkembangan akar tersebut dan hal ini dapat mempengaruhi pertumbuhan tanaman. Sejalan dengan pertumbuhan akar yang baik maka penyerapan hara akan lebih maksimal. Perlakuan pupuk $4 \mathrm{~g} /$ polybag juga memiliki nilai NPA yang lebih besar dan perlakuan tanpa pupuk memiliki nilai yang paling kecil. Hal ini serupa dengan penelitian Adinugraha (2012), pembe-rian pupuk majemuk NPK (15-15-15) dengan dosis 0,4 s/d 0,6 g/bibit berpengaruh terhadap pertumbuhan tinggi, diameter, kekokohan bibit, berat kering bibit dan indeks kualitas bibit mahoni.

Menurut Sitompul dan Guritno (1995), nilai nisbah pucuk akar yang tinggi dengan produksi biomassa total yang besar pada tanah yang subur, secara tidak langsung menunjukkan bahwa akar yang relatif sedikit, cukup untuk mendukung pertumbuhan tanaman yang relatif besar dalam menyediakan air dan unsur hara. Sedangkan tanaman yang kekurangan air dan unsur hara akan berusaha membentuk akar yang lebih banyak yang memungkinkan tanaman untuk meningkatkan serapan sehingga pada akhirnya menghasilkan nisbah pucuk akar yang rendah.

Setelah berumur 3 bulan, nilai berat kering total terbesar diperoleh pada perlakuan dosis pupuk $4 \mathrm{~g} /$ polybag, sedangkan nilai BKT terendah terdapat pada perlakuan tanpa pupuk. Pemberian pupuk yang dilakukan berpengaruh terhadap pertum-buhan pucuk bibit merbau darat, karena semakin tinggi berat kering pucuk dan akar, biomassa bibit yang dihasilkan juga semakin tinggi. Hal ini berarti bibit merbau darat mempunyai pertumbuhan yang baik. Hal ini serupa dengan penelitian Supriyanto dkk. (2014), bahwa pemberian pupuk organik cair urin sapi sebanyak $150 \mathrm{ml} / \mathrm{l}$ air berpengaruh terhadap pertambahan jumlah daun dan berat kering pucuk semai jabon.

Indeks mutu bibit merupakan salah satu indikator siap tidaknya bibit dipindah ke lapangan. Hendromono dan Durahim (2004), mengemukakan bahwa bibit yang memiliki nilai IMB minimal 0,09 akan memiliki daya tahan hidup yang tinggi apabila dipindah ke lapangan. Dalam penelitian ini, perlakuan tidak memberikan pengaruh terhadap nilai IMB, semua perlakuan memiliki IMB yang memenuhi persyaratan $(>0,09)$. Hasil ini menunjukkan bahwa bibit merbau darat sudah siap dipindah ke lapangan.

\section{KESIMPULAN}

Dari hasil penelitian, dapat disimpulkan sebagai berikut.

1. Pemberian intensitas naungan 55\% meningkatkan berat kering pucuk bibit merbau darat. 
2. Pemberian dosis pupuk NPK yang terbaik untuk meningkatkan pertumbuhan bibit merbau darat adalah $4 \mathrm{~g} /$ polybag.

\section{DAFTAR PUSTAKA}

Adinugraha, H. A. 2012. Pengaruh cara penyemaian dan pemupukan NPK terhadap pertumbuhan bibit mahoni daun lebar di persemaian. Jurnal Pemuliaan Hutan Hutan. 6(2): $1-9 \mathrm{p}$.

Hendromono. 1994. Pengaruh media organik dan tanah mineral terhadap mutu bibit Pterygota alata Roxb. Jurnal Penelitian Hutan Tanaman. 7(2):77-83 p.

Hendromono dan Durahim. 2004. Pemanfaatan limbah sabut kelapa sawit dan sekam padi sebagai medium pertumbuhan bibit mahoni afrika (Khaya anthocela.C.DC). Buletin Penelitian Hutan no 644. Badan Litbang Kehutanan. Puslitbang Hutan dan Konservasi Alam. Bogor.

Indriyanto. 2013. Teknik dan Manajemen Pesemaian. Buku. Lembaga Penelitian Universitas Lampung. $270 \mathrm{p}$.

Kurniaty, R. dan Danu. 2012. Teknik persemaian. Booklet. Balai Penelitian Teknologi Perbenihan Tanaman Hutan. Bogor. 98 p.

Martawijaya, A., I. Kartasudjana, Y.I. Mandang, S.A. Prawira, dan K. Kadir. 2005. Atlas Kayu Indonesia, Jilid II. Buku. Pusat Penelitian dan Pengembangan Hasil Hutan. Bogor. 91-96 p.

Panjaitan, S., R. S. Wahyuningtyas, dan D. Ambarawati. 2011. Pengaruh naungan terhadap proses ekofisiologi dan pertumbuhan Shorea selanica (DC.) Blume di persemaian. Jurnal Penelitian Dipterokarpa. 5(2):73-82 p.

Rahmawati, V., Sumarsono, dan W. Slamet. 2013. Nisbah daun batang, nisbah tajuk akar dan kadar serat kasar alfalfa (Medicago sativa) pada pemupukan nitrogen dan tinggi defoliasi berbeda. Animal Agriculture Journal. 2(1): 1-8 p.

Setyanti, Y. H., S. Anwar, dan W. Slamet. 2013. Karakteristik fotosintetik dan serapan fosfor hijauan alfalfa (Medicago sativa) pada tinggi pemotongan dan pemupukan nitrogen yang berbeda. Journal Animal Agricultur. 2(1):86-96 p.

Sitompul, S.M, dan B. Guritno.1995. Analisis Pertumbuhan Tanaman. Buku. Gadjah Mada University Press. Yogyakarta. 412 p.

Supriyanto., Muslimin., dan H. Umar. 2014. Pengaruh berbagai dosis pupuk organik cair urin sapi terhadap pertumbuhan semai jabon merah (Anthocephalus macrophyllus (Roxb.) Havil). Warta Rimba. 2(2):149-157 p.

Wardiana, E. dan M. Herman. 2009. Pengaruh naungan dan media tanam terhadap pertumbuhan bibit Kemiri Sunan (Reutealis trisperma) (BLANCO) Airy Shaw. Buletin RISTRI. 1(4): 197-205 p. 